\title{
Create a good learning environment and motivate active learning enthusiasm
}

Weihong Bi, Guangwei Fu, Xinghu Fu, Baojun Zhang, Qiang Liu, et al.

Weihong Bi, Guangwei Fu, Xinghu Fu, Baojun Zhang, Qiang Liu, Wa Jin, "Create a good learning environment and motivate active learning enthusiasm," Proc. SPIE 10452, 14th Conference on Education and Training in Optics and Photonics: ETOP 2017, 104526B (16 August 2017); doi: $10.1117 / 12.2269933$

SPIE Event: 14th Conference on Education and Training in Optics and Photonics, ETOP 2017, 2017, Hangzhou, China 


\title{
Create a good learning environment and motivate active learning
}

\section{enthusiasm}

\author{
Weihong Bi*, Guangwei Fu, Xinghu Fu, Baojun Zhang, Qiang Liu, Wa Jin \\ School of Information Science and Engineering, The Key Laboratory for Special Fiber and Fiber \\ Sensor of Hebei Province, Yanshan University, Qinhuangdao 066004, China
}

\begin{abstract}
In view of the current poor learning initiative of undergraduates, the idea of creating a good learning environment and motivating active learning enthusiasm is proposed. In practice, the professional tutor is allocated and professional introduction course is opened for college freshman. It can promote communication between the professional teachers and students as early as possible, and guide students to know and devote the professional knowledge by the preconceived form. Practice results show that these solutions can improve the students interest in learning initiative, so that the active learning and self-learning has become a habit in the classroom.
\end{abstract}

key words learning environment; learning enthusiasm; active learning; self-learning

\section{INTRODUCTION}

At present, with the rapid development of social economy and technology, everyone life has been surrounded and occupied a lot of time by the Internet, WeChat, QQ, online games, online shopping and so on. Twenty years ago, people lives can not be separated from electricity. However, modern life can not be separated from the phone. For this reason, a large number of people called the Phubbing. The development of network information for people to provide information and shopping convenience, but also often attract people to spend a lot of energy in the browse all kinds of information and website, which results in students absent phenomenon gradually increased, especially in the fourth grade of university teaching has many abnormal phenomena. For instance, firstly, class attendance is very low, senior students or review for entrance exams, or go out for a job, frequent truancy has become an indisputable fact that attendance is less than half of the situation is very common. Secondly, the marginalization of graduation design, the students do not attach importance to the graduation design, do not invest, the quality of a serious decline. How to change the senior phenomenon, regain the enthusiasm of the students on the professional course of study.

In order to improve the quality of the curriculum and graduation design, the training of engineering talents of high quality, which are the important questions that every teacher who works in the teaching line is thinking positively. The following are the views of our research group on the two issues of the reasons for the lack of enthusiasm for learning and how to improve the enthusiasm of the students.

*bwhong@ysu.edu.cn;

14th Conference on Education and Training in Optics and Photonics: ETOP 2017, edited by Xu Liu,

Xi-Cheng Zhang, Proc. of SPIE Vol. 10452, 104526B - ( 2017 ICO, IEEE, OSA, SPIE

CCC code: $0277-786 X / 17 / \$ 18 \cdot$ doi: $10.1117 / 12.2269933$

Proc. of SPIE Vol. 10452 104526B-1 


\section{INVESTIGATION ON THE REASONS OF THE LOW LEARNING INITIATIVE}

In order to make the survey data more objective and comprehensive, the project team carry out the investigation work from multiple perspectives, mainly in the study situation of senior students of Yanshan University, the situation of teaching senior students of other university and the situation of the learning in different course. An anonymous questionnaire survey was conducted among 2000 students in 40 universities, part of the result shows: the students who absent from class over 50\% play truant from 37\% compulsory course and 43\% selective course, an shown in Table 1. The investigation on the reasons of cutting class indicate that $(31.47+11.89) \%=43.63 \%$ of the students are not interested in student content, addicted to the game, as shown in Table 2. It is meaningful to establish the methods and measures that can attract learning and arouse the enthusiasm of learning.

Table 1 Situation about truancy and absent

\begin{tabular}{ccccc}
\hline & Less than 10\% & About 30\% & About 50\% & Over 70\% \\
\hline Compulsory course & $45.45 \%$ & $17.48 \%$ & $22.38 \%$ & $14.69 \%$ \\
Selective course & $27.97 \%$ & $27.97 \%$ & $18.88 \%$ & $24.48 \%$ \\
\hline \multicolumn{4}{c}{ Table 2 Reason for truancy and absent } \\
\hline \multirow{2}{*}{ Bad teaching } & No interest in & Review to postgraduate & Addicted to other things \\
& course content & and recruitment & \\
\hline $11.89 \%$ & $31.47 \%$ & $48.04 \%$ & $11.89 \%$ \\
\hline
\end{tabular}

\section{CREATE A GOOD LEARNING ENVIRONMENT, STIMULATE THE ENTHUSIASM OF ACTIVE LEARNING}

In order to improve students learning enthusiasm, our group conducted a lot of thinking and exploration, such as improving the student teaching model, taking Flipped Classroom into the teaching process, strengthening the guidance of the practical issues, increasing the teacher sense of responsibility and so on. We have achieved some results, this paper describes the create a good learning environment, to stimulate the enthusiasm of active learning. The create a good learning environment includes the following 2 aspects:

(1) The professional teacher in contact with the students in advance of time and preconceived guide students. In order to effectively guide the students love for the professional knowledge, we have selected a professional mentor for each student. The mentor communicates with the student at least once each semester. We have increased the professional introductory course teaching by the professional senior, high and professional teachers, to stimulate students professional awareness and desire for professional knowledge.

(2) We establish a wealth of online learning resources, so that students can access the knowledge content from anywhere, such as in the professional classroom, laboratory corridors to lay the professional knowledge of the glorious history and modern application, so that students can achieve professional knowledge from everywhere, as shown in Fig.1. The establishment of abundant online resources-professional short video, professional experimental video, professional use of related instrument video, professional science animation, professional courses PPT and other information, students 
can view their expertise from anywhere, as shown in Fig.2. Open laboratory, subject research laboratory for students, from the basic support for students to understand the professional, professional love, and the establishment of innovation fund to support students desire to seek knowledge. Moreover, we organize various forms of professional knowledge to form a group effect, as shown in Fig.3.
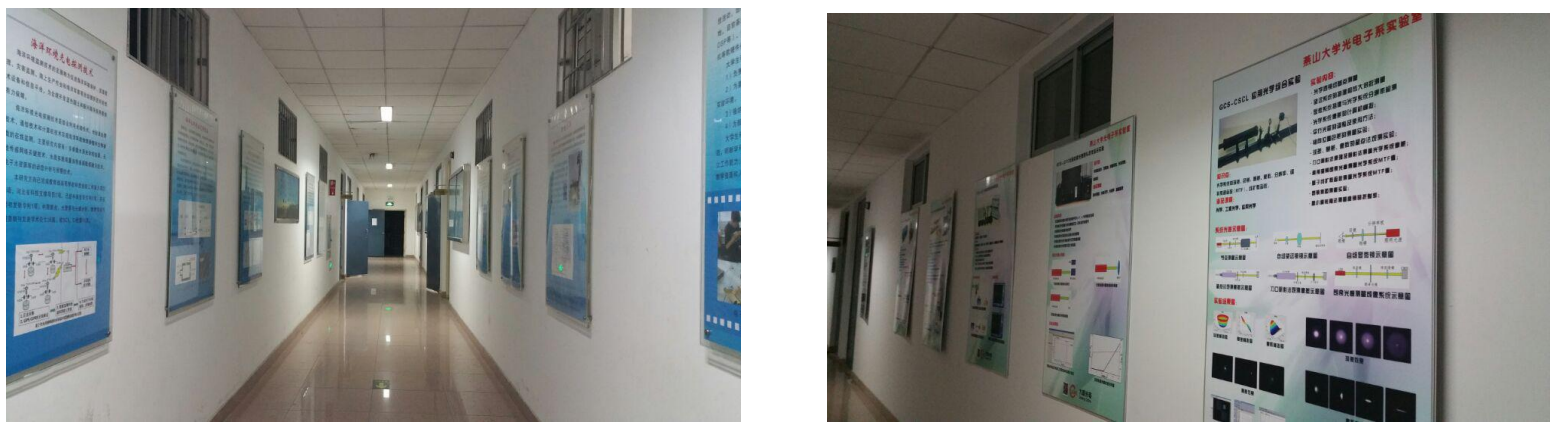

Fig.1 The access the knowledge content from anywhere

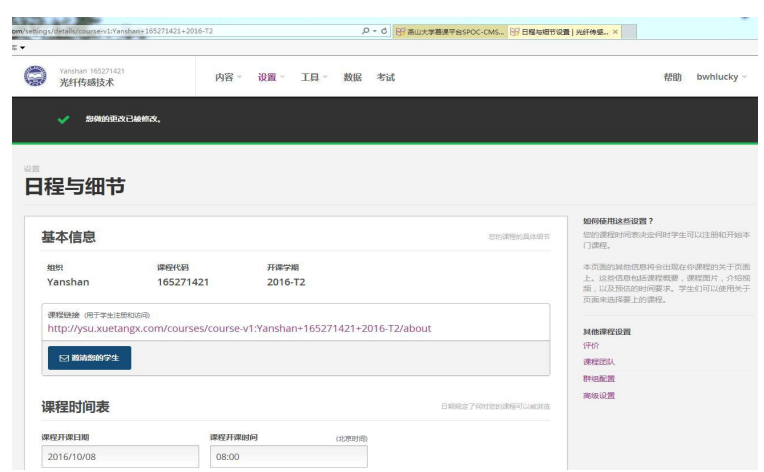

a) Online course study

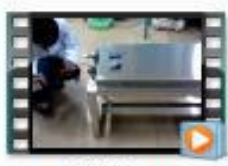

1-载氢.wmv

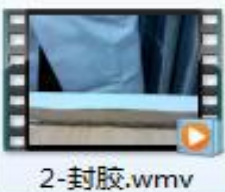

2-封胶.wmv

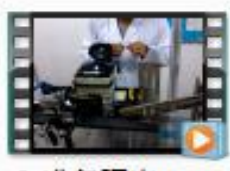

3-准备曝光.wmv

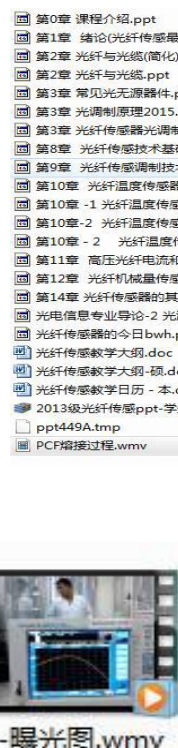

4-曝光图.wmv b) Teaches PPT
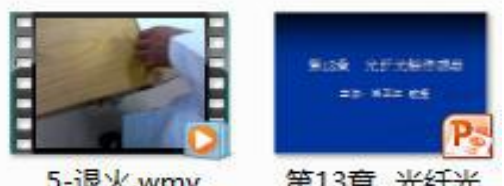

第13章 光纤光 棚传感器1.ppt

c) Online experimental video

Fig.2 The abundant laboratory resources

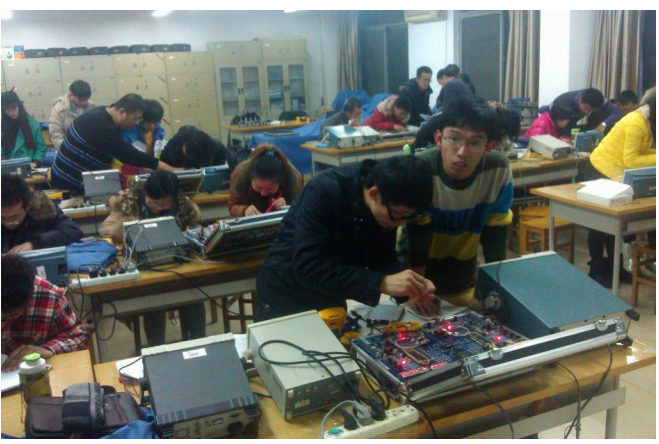

a) Laboratory

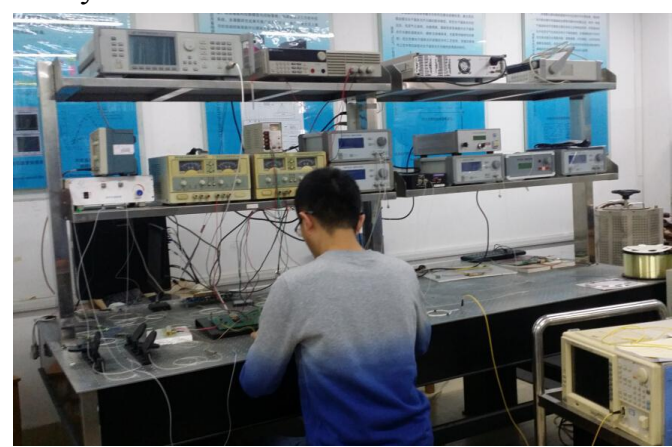

b) Research room 


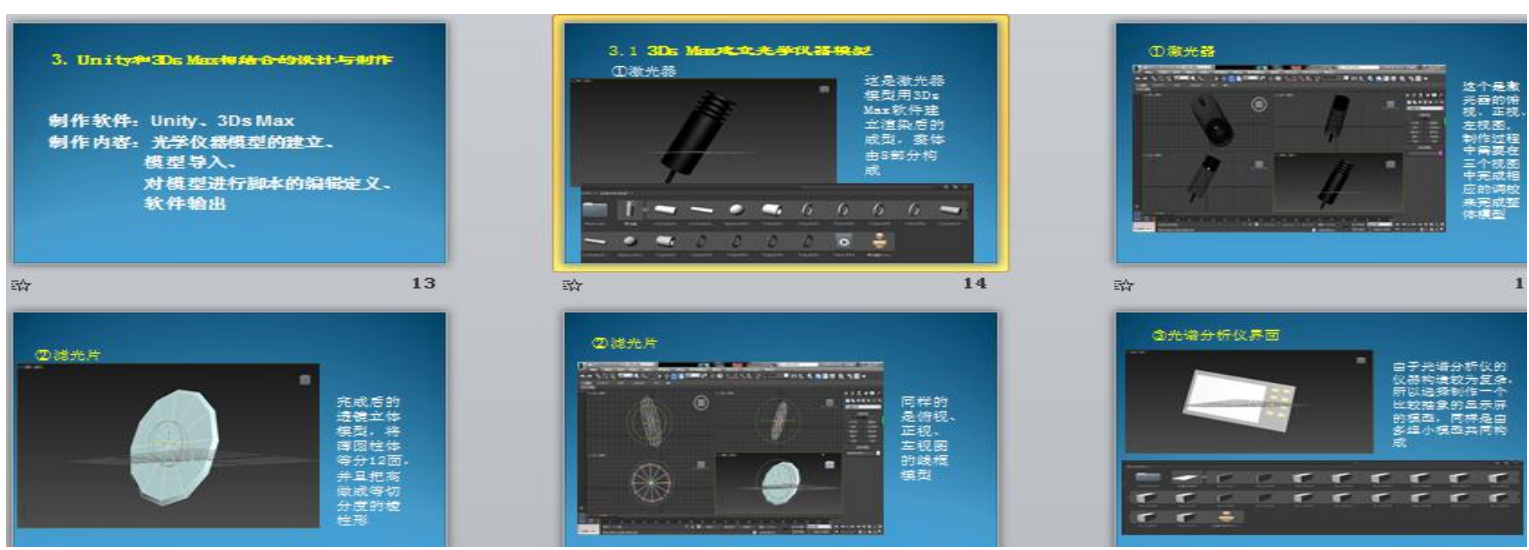

c) Online virtual lab

Fig.3 Experiment everywhere (online and offline) can be done

\section{CONCLUSION}

Through our practice, we can see that the earlier the professional teachers and students contact, the higher the students love for the major. The earlier the students go into the professional laboratory, the more time they get to know the profession. It is one of the effective ways for our teachers to create a good learning environment and stimulate the enthusiasm of active learning. The students is encouraged to join the scientific research assistants, which means the learning by watching. Practice results show that these solutions can improve the students interest in learning initiative, so that the active learning and self-learning has become a habit in the classroom. 